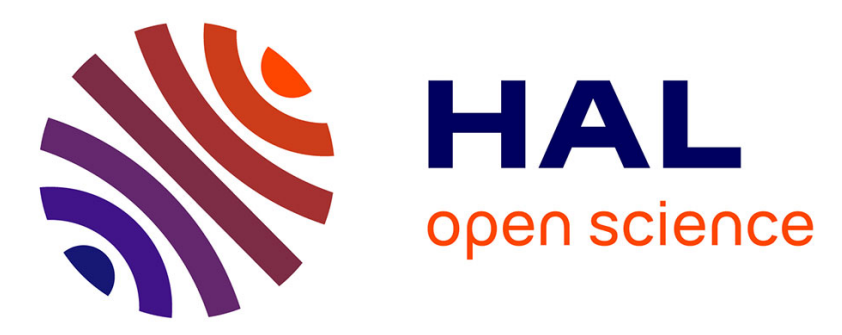

\title{
Functional relevance of computational fluid dynamics in the field of nasal obstruction: A literature review
}

Thomas Radulesco, Lionel Meister, Gilles Bouchet, Jérome Giordano, Patrick

Dessi, Pierre Perrier, Justin Michel

\section{- To cite this version:}

Thomas Radulesco, Lionel Meister, Gilles Bouchet, Jérome Giordano, Patrick Dessi, et al.. Functional relevance of computational fluid dynamics in the field of nasal obstruction: A literature review. Clinical Otolaryngology, 2019, 44, pp.801 - 809. 10.1111/coa.13396 . hal-03198716

\section{HAL Id: hal-03198716 https://hal.science/hal-03198716}

Submitted on 15 Apr 2021

HAL is a multi-disciplinary open access archive for the deposit and dissemination of scientific research documents, whether they are published or not. The documents may come from teaching and research institutions in France or abroad, or from public or private research centers.
L'archive ouverte pluridisciplinaire HAL, est destinée au dépôt et à la diffusion de documents scientifiques de niveau recherche, publiés ou non, émanant des établissements d'enseignement et de recherche français ou étrangers, des laboratoires publics ou privés. 


\title{
Functional relevance of computational fluid dynamics in the field of nasal obstruction: A literature review
}

\author{
Thomas Radulesco $^{1,2}$ (D) | Lionel Meister ${ }^{2}$ | Gilles Bouchet ${ }^{2}$ | Jérôme Giordano ${ }^{2}$ | \\ Patrick Dessi $^{1}$ | Pierre Perrier ${ }^{2}$ | Justin Michel ${ }^{1,2}$
}

\author{
${ }^{1}$ Department of Oto-Rhino-Laryngology \\ and Head and Neck Surgery, APHM, La \\ Conception University Hospital, Marseille, \\ France \\ ${ }^{2}$ IUSTI, Aix-Marseille University, Marseille, \\ Cedex, France \\ Correspondence \\ Thomas Radulesco, Department of Oto- \\ Rhino-Laryngology and Head and Neck \\ Surgery, La Conception University Hospital, \\ 147 Bd Baille, 13005 Marseille, France. \\ Emails: thomas.radulesco@ap-hm.fr; \\ thomas.radulesco@gmail.com
}

\begin{abstract}
Background: Nasal airway obstruction (nasal obstruction) is a common symptom affecting the quality of life of patients. It can be estimated by patient perception or physical measurements. Computational fluid dynamics (CFD) can be used to analyse nasal ventilation modalities. There is a lack of comparative studies investigating the correlations between CFD variables and patient perception or physical measurements. Objective of the review: Our goal was to define correlations between CFD variables and patient perception and physical measurements. We also aimed to identify the most reliable CFD variable (heat flux, WSS, total pressure, temperature...) characterising nasal breathing perception.

Type of review: Systematic literature review using PRISMA guidelines.

Search strategy: The selected studies were obtained from the US National Library of Medicine (PubMed) online database, MEDLINE (Ovid), Google Scholar and the Cochrane Library using a combination of MeSH terms (nose, paranasal sinus, fluid dynamics, rhinology) and non-MeSH terms (CFD, nasal airway, nasal airflow, numerical, nasal symptoms). Studies that did not incorporate objective or subjective clinical assessment were excluded.
\end{abstract}

Evaluation method: We compared all results obtained by authors regarding CFD variables and assessment of nasal airway obstruction (clinical or physical).

Results: To compare nasal obstruction with CFD variables, most authors use CFD-calculated nasal resistances, airflow, heat flux, wall shear stress, total pressure, velocities and streamlines. We found that heat flux appears to be the CFD variable most closely correlated with patient perception. Total pressure, wall shear stress and velocities are also useful and show good correlations. Correlations between CFD-calculated nasal resistances and patient perception are stronger after correction of the nasal cycle.

Conclusions: The growing number of CFD studies on the nose has led to a better understanding of nasal obstruction. The clinical interpretation of previously unknown data, such as WSS and heat flux, is opening up new horizons in the understanding of this symptom. Heat fluxes are among the best CFD values correlated with patient perception. More studies need to be performed including temperature and humidity exchanges. 


\section{1 | INTRODUCTION}

Nasal airway obstruction is a common symptom affecting patient quality of life. ${ }^{1}$ It may involve different aetiologies including septal deviations, nasal valve collapse or inferior turbinal hypertrophy. ${ }^{2}$ To date, the evaluation of nasal obstruction has been subjective, through self-questionnaires (NOSE, SNOT 22) and/or the visual analog scale (VAS), or has been performed using various physical tests such as rhinomanometry and peak nasal inspiratory flow (PNIF). ${ }^{3-5}$

The use of fluid dynamics to simulate airflow in the nasal cavity was widely adopted during the 2000s. Computational fluid dynamics (CFD) consists in analysing fluid flows, or their effect, by numerical solution of equations governing fluids. Applied to nasal cavities, CFD is designed to produce accurate models of airflow and air-conditioning. The CFD process includes the importation of DICOM data (most often from CT scans), three-dimensional modelisation and definition of boundary conditions. Boundary conditions define the inputs of the simulation model (ie pressure, air and wall temperature), thus allowing nasal breathing to be simulated. In this way, CFD offers practitioners a new tool for nasal ventilation analysis.

Over the past 10 years, many studies have been published focusing on CFD in the nasal airway. ${ }^{6,7}$ Computational fluid dynamics has enabled a better understanding of nasal physiology, computing wellknown variables such as nasal airflow and nasal resistances, as well as new variables, for example, heat flux, which represents heat transfers between air and nasal mucosa, or wall shear stress (WSS), which measures friction between the fluid and the wall. These variables are not currently in use in the medical field or in clinical routine., 8

As a new tool, CFD is confronted by existing gold standards in the field of nasal obstruction assessment. However, to date, it remains unclear how CFD variables can be correlated with patient perception or with physical measurements carried out in clinical routine. ${ }^{10}$ The correlation between clinical evaluation of nasal breathing and CFD is a key to improving interpretation of the latter. In the published literature, there is a dearth of comparative studies analysing correlations between patient nasal breathing perception and CFD, as reported by Leite et al in their recent literature review. ${ }^{11,12}$

We conducted a literature review of CFD studies regarding the nasal airway, focusing on articles comparing clinical data with CFD. The goal was to define correlations between CFD variable and patient nasal obstruction perception or physical measurements. We also aimed to identify the most reliable CFD variable (heat flux, WSS, total pressure, temperature...) characterising nasal obstruction.

\section{2 | METHODS}

\section{1 | Selection of studies}

The literature review was performed according to PRISMA guidelines. ${ }^{13}$ The selected studies were obtained from the US National Library of Medicine (PubMed) online database, MEDLINE (Ovid), Google Scholar and Cochrane Library using a combination of MeSH

\section{Keypoints}

- Computational fluid dynamics (CFD) consists in studying fluid flows, or their effect, by numerical solution of equations governing fluids. It can be used to study nasal ventilation modalities.

- The correlation between clinical evaluation of nasal breathing and CFD is a key to improving the interpretation of the latter. In the published literature, there is a lack of comparative studies analysing correlations between patient nasal breathing perception and CFD.

- Heat flux appears to be the best CFD variable correlated with patient perception. Total pressure, wall shear stress and velocities are also useful and show good correlations.

- CFD-calculated nasal resistances are heterogeneously correlated with patient impairment.

- CFD must integrate new types of variable such as hygrometry, which measures the humidity in the atmosphere, or take into account variations of nasal mucosal temperature according to inspiration or expiration.

terms (nose, paranasal sinus, fluid dynamics, rhinology) and non$\mathrm{MeSH}$ terms (CFD, nasal airway, nasal airflow, numerical, nasal symptoms). Studies that did not incorporate more than 5 subjects and objective or subjective clinical assessment were excluded.

Ranges of Pearson correlation between clinical assessment and CFD variables were considered perfect if $|r|=1$, very strong if $|r|>$ 0.8 , strong if $0.5>|r|>0.8$, moderate if $0.2>|r|>0.5$, low if $|r|<0.2$ and null if $r=0$.

\section{3 | RESULTS}

\section{1 | Article selection}

Table 1 lists all selected studies and their assessment method for clinical evaluation of nasal obstruction. Of the 258 articles selected, 47 dealt with CFD and nasal airway. Ten out of 47 included CFD and subjective or objective nasal obstruction clinical measurements data (Figure 1). The present review summarised the correlation between clinical assessment of nasal obstruction and CFD results. No time filter was used on included studies.

\subsection{Nasal airway obstruction: clinical assessment}

Clinical assessment of nasal obstruction can be performed using many tools. For subjective assessment, most authors used the NOSE (Nasal Obstruction Symptom Evaluation) questionnaire and/or the VAS scale. ${ }^{14,15}$ The NOSE questionnaire is a disease-specific quality-of-life instrument for nasal obstruction that has been validated in the literature. ${ }^{16,17}$ Other authors used the SNOT-22 questionnaire or 
TAB LE 1 Clinical assessment of NAO in the 10 published studies included in this review

\begin{tabular}{|c|c|c|c|c|}
\hline \multirow[b]{2}{*}{ Article } & \multirow{2}{*}{$\begin{array}{l}\text { Number of } \\
\text { patients }\end{array}$} & \multirow[b]{2}{*}{ Type of patient } & \multicolumn{2}{|l|}{ Clinical evaluation of NAO } \\
\hline & & & Subjective & Objective \\
\hline Casey et al $\left.\right|^{21}$ & 30 & $\begin{array}{l}\text { Anatomic nasal obstruction (deviated septum, turbi- } \\
\text { nate hypertrophy or nasal valve dysfunction) versus } \\
\text { healthy subjects }\end{array}$ & NOSE/VAS & / \\
\hline Gaberino et $\mathrm{al}^{22}$ & 12 & $\begin{array}{l}\text { Anatomic nasal obstruction (deviated septum, turbi- } \\
\text { nate hypertrophy) with significant nasal cycle }\end{array}$ & NOSE/VAS & / \\
\hline Kimbell et al $\left.\right|^{8}$ & 10 & $\begin{array}{l}\text { Anatomic nasal obstruction (deviated septum } \pm \text { turbi- } \\
\text { nate hypertrophy) }\end{array}$ & NOSE/ VAS & / \\
\hline Li, Farag, Leach et al ${ }^{30}$ & 28 & Empty nose syndrome versus healthy subject & NOSE/ SNOT-22/ ENS6Q & $\begin{array}{l}\text { Rhinomanometry/ } \\
\text { Acoustic rhinometry }\end{array}$ \\
\hline Li, Farag, Maza et al ${ }^{31}$ & 69 & Empty nose syndrome versus healthy subject & NOSE/ SNOT-22/ ENS6Q & / \\
\hline Sullivan et al ${ }^{37}$ & 10 & $\begin{array}{l}\text { Anatomic nasal obstruction (deviated septum, turbi- } \\
\text { nate hypertrophy or nasal valve dysfunction) }\end{array}$ & NOSE/VAS & / \\
\hline Zhao et $\mathrm{al}^{26}$ & 22 & Healthy subject & VAS & Rhinomanometry \\
\hline
\end{tabular}

FIGURE 1 PRISMA flow diagram

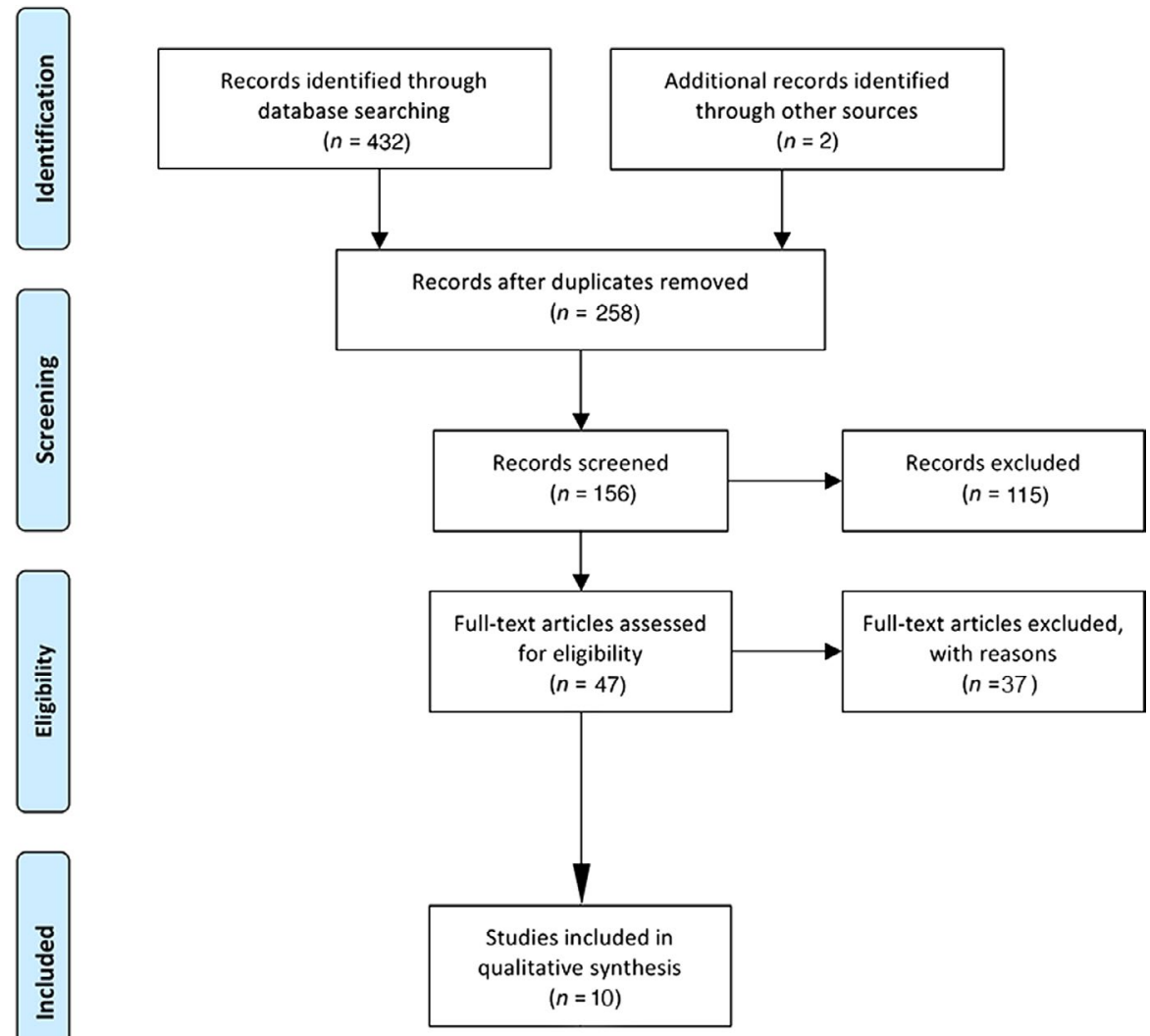

more specific surveys such as the ENS6Q questionnaire for empty nose syndrome (ENS) patients. ${ }^{18,19}$

Among the physical tests, the most frequently used tool remains rhinomanometry, which measures pressure and flow through the nose during normal inspiration and expiration. ${ }^{4}$ Acoustic rhinometry measures the cross-sectional area and length of the nose and the nasal cavity by means of acoustic reflections. It can be correlated with minimal cross-sectional area (MCAs) and is also used for functional assessment, although it is in fact a morphological examination. ${ }^{20}$ We found no study related to PNIF. 


\section{3 | CFD calculations}

The main data measured using CFD were as follows:

- Airflow (uni- or bilateral, in $\mathrm{mL} / \mathrm{s}$ ), and airflow partitioning (\%) corresponding to the balance between obstructed and non-obstructed nasal fossae.

- Nasal resistance (CFD-NR) to uni- or bilateral inspiration and expiration, (sPa/mL): Nasal resistances were expressed as $R=\frac{\Delta P}{V}$, where $\Delta P$ is the pressure differential between the nostril and the rhinopharynx and $V$ is the airflow rate.

- Heat transfer (measure of the heat loss from the nasal mucosa to the inspired air) can be studied by:

o Total heat flux $\left(\mathrm{W} / \mathrm{m}^{2}\right)$, calculated as the rate of heat loss from the nasal mucosa to inspired air between entry of the nostrils and the choana, divided by the corresponding surface area.

o SAHF50, that is, the surface area where heat flux $>50 \mathrm{~W} / \mathrm{m}^{2}$.

o Peak heat flux defined as the value above which only $1 \mathrm{~cm}^{2}$ of mucosa is exposed.

- Total pressure $(\mathrm{Pa})$, that is, the measure of total energy of the airstream, is equal to static pressure plus velocity pressure.

- Wall shear stress (WSS) (Pa), that is, a friction force generated when moving air enters into contact with the nasal walls.

- Air velocity $(\mathrm{m} / \mathrm{s})$ and maximal velocity $(V \max )$, that is, the distance travelled per unit of time.

Streamlines corresponding to intranasal airflow distribution and allowing airflow visualisation (Video S1).

\subsection{Correlation between CFD and clinical assessment}

\subsection{1 | Airflow}

Casey et $\mathrm{al}^{21}$ found strong correlations between unilateral nasal airflow and NOSE $(r=-0.55, P=0.0016)$ and moderate correlations between unilateral nasal airflow and VAS $(r=-0.49, P=0.0056)$. For Gaberino et al, ${ }^{22}$ correlations with NOSE and VAS were strong after virtual correction of the nasal cycle $(r=-0.61, P=0.002$ and $r=0.56, P=0.04$, respectively). Before virtual correction, airflow was moderately correlated with NOSE $(r=-0.41, P=0.048)$ but not significantly correlated with VAS. Kimbell reported a strong correlation between NOSE and airflow $(r=-0.70){ }^{8}$ In patients improved after surgery for nasal obstruction, several studies found improved airflow on the narrow side and deteriorated airflow on the non-narrow side after surgery. . $^{83,24}$

\subsection{2 | CFD-calculated nasal resistances}

Nasal resistances are among the most analysed data in the literature concerning nasal obstruction. ${ }^{25}$ Authors found heterogeneous results for correlations between CFD-calculated nasal resistances (CFD-NR) and nasal airflow sensation. Casey et al found statistically significant higher CFD-NR in patients complaining of nasal obstruction compared to patients without nasal obstruction $(P=0.0006) .{ }^{21}$ However, in their study on 30 individuals (15 patients with nasal obstruction and 15 without), no correlation was found between CFD-NR and NOSE or VAS. Before virtual correction of the nasal cycle, Gaberino et al found no correlation between CFD-NR and NOSE or VAS. However, after virtual correction of the nasal cycle, CFD-NR was strongly correlated with NOSE and VAS $(r=0.55, P=0.005$ and $r=-0.58, P=0.003$, respectively). ${ }^{22}$ Kimbell et $\mathrm{al}^{8}$ found a moderate correlation between CFD-NR and both NOSE and VAS $(r=0.48$ and $r=-0.42$, respectively).

Regarding comparison between rhinomanometry and CFD-NR, Zhao et $\mathrm{al}^{26}$ found a moderate correlation $(r=0.41, P<0.05)$. Lu et $\mathrm{al}^{27}$ found no significant differences between rhinomanometry and CFD-NR, but correlations were not evaluated $(P>0.05)$.

\subsection{3 | Heat transfer: total heat flux, SAHF50, peak heat flux}

Heat flux analysis now occupies a major place in CFD applied to nasal obstruction. Different methods are available to calculate heat transfer, and results seem to correlate well with patient perception, whatever the method used. In Casey's study, NOSE and VAS were moderately correlated with total unilateral heat flux $(r=-0.48$, $P=0.0075$ and $r=0.43, P=0.0166$, respectively) and strongly with SAHF50 $(r=-0.55, P=0.0016$ and $r=-0.51, P=0.0038$, respectively). ${ }^{21}$ Sullivan et al reported that, among all heat flux measures, SAHF50 had the best correlation with NOSE $(r=-0.76$, $P<0.0001)$ and VAS $(r=0.63, P=0.002) .{ }^{27}$ Gaberino et al found a statistically significant difference between pre- and postoperative analyses for heat flux $(P=0.027)$. In their study, after correction of the nasal cycle, heat flux was strongly correlated with NOSE and VAS ( $r=-0.51$ and $r=0.51$, respectively, $P=0.011$ ) but SAHF50 was only moderately correlated with NOSE $(r=-0.43, P=0.34) .{ }^{21}$ For Zhao et al, ${ }^{26}$ only peak nasal mucosal heat loss posterior to the nasal valve was moderately correlated with VAS score $(r=-0.46$, $P<0.01)$.

\subsection{4 | Pressure}

Kim et al ${ }^{24}$ compared three symptomatic patients with three asymptomatic patients. They also found a greater pressure drop in patients with nasal obstruction $(P<0.05)$. The pressure distribution led this author to conclude that the nasal valve is a key zone for nasal obstruction, as shown elsewhere. ${ }^{28}$

\subsection{5 | Maximum velocity}

For Kim et al, ${ }^{24}$ Maximum velocity (Vmax) was higher in patients with septal deviation $(P=0.05)$. Vmax was also correlated with anatomical findings: when the septal deviation was caudal, Vmax and symptoms were higher than in posterior septal deviation. ${ }^{29}$ 

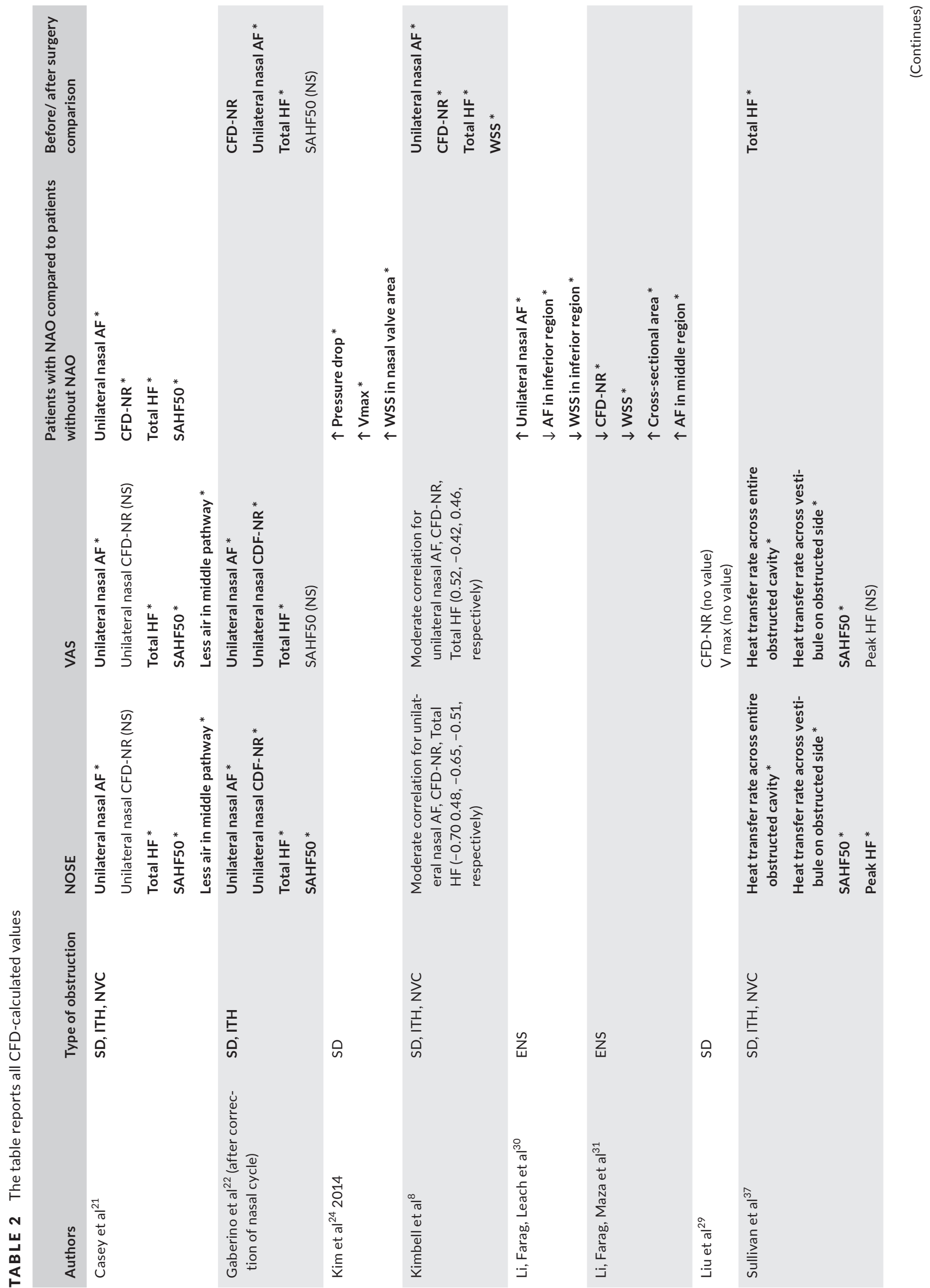

ڤิ

Z
I
ज
जि
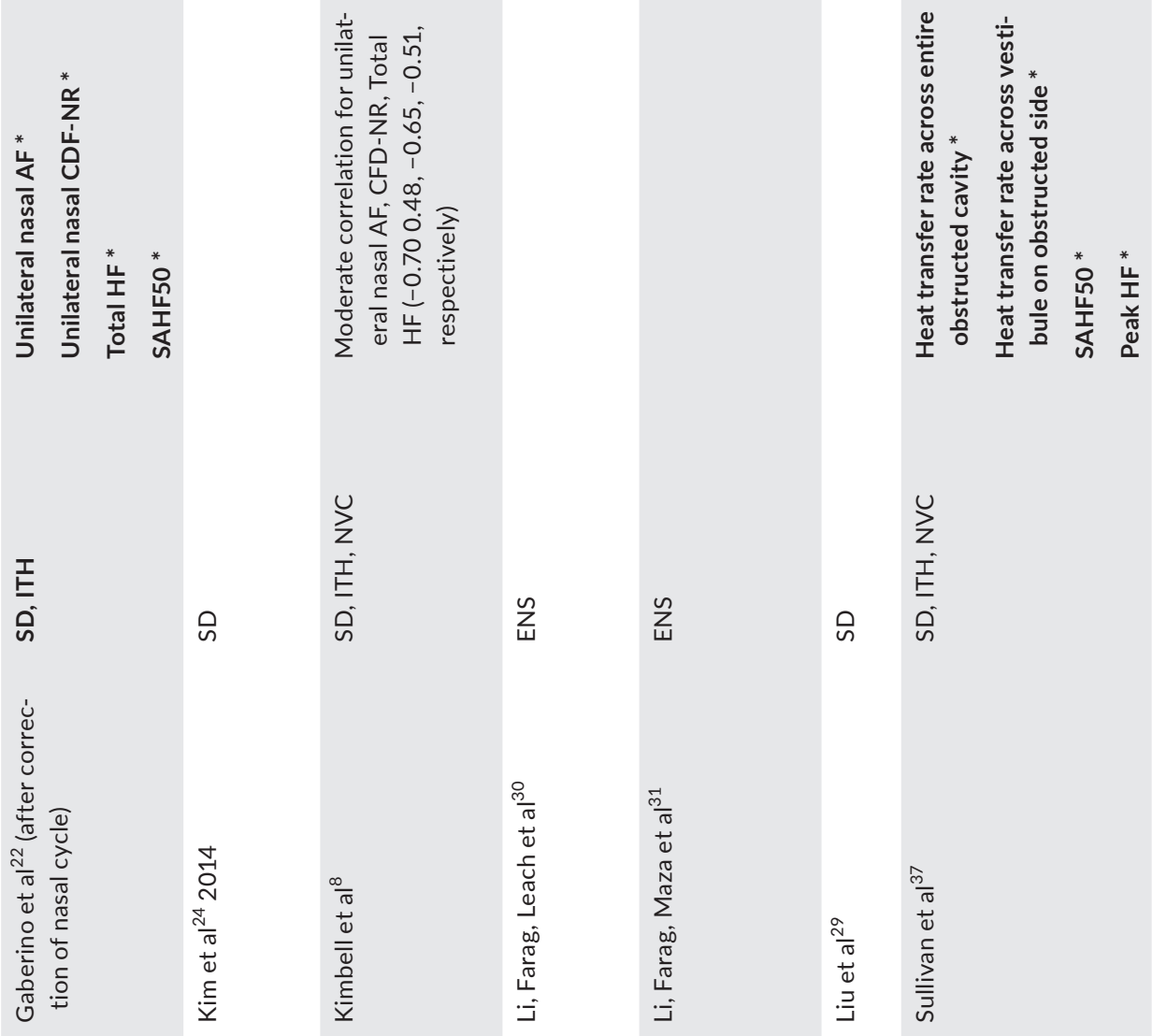


\subsection{6 | Wall shear stress}

Kimbell et $\mathrm{al}^{8}$ found that wall shear stress (WSS) calculated on the obstructed side was strongly correlated with NOSE $(r=-0.51)$ and moderately with VAS $(r=0.32)$. Kim et $a^{24}$ reported higher shear stress values in symptomatic patients than in asymptomatic patients (0.564-0.943 Pa vs 0.368-0.461 Pa, $P=0.050$ ). In patients with nasal airway obstruction due to ENS, WSS was lower in the inferior region, due to absence of inferior turbinates. ${ }^{30,31}$

\subsection{7 | Intranasal airflow distribution}

Regarding the nasal airway, in patients with nasal obstruction, middle pathway airflow was lower than in individuals without nasal obstruction ( $31 \pm 18 \mathrm{~mL} / \mathrm{s}$ vs $68 \pm 10 \mathrm{~mL} / \mathrm{s}, P<0.001)$; middle pathway airflow was strongly correlated with NOSE $(r=-0.76, P<0.001)$ and VAS scores $(r=0.64, P<0.0001) .{ }^{21}$ In a more specific population of ENS patients, Li et $\mathrm{al}^{31}$ found an unexpected change in airflow when the inferior turbinate was missing: they observed a strong diminution of airflow in the inferior region and an augmentation of airflow in the middle region $(P<0.05)$.

\section{DISCUSSION}

\section{1 | Synopsis of new findings}

One of the difficulties regarding outcomes of aesthetic and/or functional surgery is the objectivity of the evaluations carried out and their correlation with patient perception. ${ }^{32}$ While self-evaluation using quality-of-life questionnaires remains the gold standard, results of objective measurements such as rhinomanometry remain controversial. ${ }^{33}$ CFD offers a new method for evaluating nasal airflow that shows an interesting correlation with current patient-reported outcomes. The advantage of CFD lies not only in the airflow analysis it provides but also in airflow conditioning. ${ }^{34}$ This innovative approach is very useful since data such as heat flux are not measurable by conventional investigations.

\subsection{Summary of main results}

Recent studies evidenced the great interest showsn in heat flux in rhinology. ${ }^{21,22,30,31,35,36}$ Heat flux could be likened to the feeling of cold felt by the patient during inspiration. In the studies reviewed, all data allocated a major role to heat flux in the genesis of nasal obstruction perception (Table 2). Different versions of heat flux can be used (total heat flux, SAHF50, peak heat flux), each of which has shown a statistically significant correlation with patient perception. ${ }^{37}$ This suggests that nasal obstruction is related to a lack of cooling effect rather than to high nasal resistance. Perhaps, after all, the truth lies in a combination of both. ${ }^{34}$

Regarding comparisons between patient perception and nasal resistances, several authors concorded that unilateral evaluation 
is more reliable than bilateral evaluation. ${ }^{38}$ Consequently, it is necessary to focus on narrow side and non-narrow side rather than on total airflow or total nasal resistance. ${ }^{22}$ The main criticism that can be directed at questionnaires (except the VAS scale) is that they do not lateralise the more obstructed side, whereas CFD data focus most often on unilateral exploration. We therefore compare overall perception with unilateral analyses. In most studies, there was a significant improvement after surgery on the narrow side although contralateral deterioration was often found (due to medialisation of the nasal septum), while patients did not report nasal impairment. Therefore, it appears important to take into account the balance of airflow partitioning. Analysis of correlations between CFD-NR and patient perception reveals heterogeneous results. Many reasons can account for these discrepancies. Firstly, the sensation of nasal obstruction is not only due to an increase in nasal resistances. This is why clinical measurements such as rhinomanometry are discussed. ${ }^{39,40}$ Secondly, it is necessary to pay close attention to the nasal cycle in CFD studies as this can constitute a confounding factor. ${ }^{22,41,42}$ Thirdly, tissue compliance is currently not considered in CFD studies, which assumes only rigid walls. It is acknowledged that nasal obstruction problems due to the nasal valve may be either static or dynamic. ${ }^{43,44}$ If static (architectural), problems can be efficiently explored using CFD; simulation of a nasal valve collapse appearing during breathing would entail modelling deformable walls according to the airflow.

The nasal valve area is key in the perception of nasal obstruction, in which pressure and velocity analyses are linked to nasal obstruction perception. ${ }^{24,29,43,45,46}$ Measuring pressures and velocities is not difficult and should be systematically undertaken when performing CFD.

Wall shear stress increases in cases of septal deviation or nasal valve collapse and diminishes to minimum value in the absence of obstruction. ${ }^{24,31,47}$ However, while the above-mentioned results seem interesting, WSS suffers from a major limitation in as far as it is invalid in the presence of total nasal obstruction. Indeed, when there is septal deformation, findings are generally increased, whereas, in the absence of airflow, WSS is null and therefore difficult to correlate with clinical discomfort.

Concerning intranasal airflow distribution, several authors reported a strong correlation between the patient's obstruction and the path taken by the air inside the nasal cavity: patients with a decreased flow at the middle meatus appeared more uncomfortable. ${ }^{21}$ Conversely, in ENS patients, the flow in the middle meatus increases. ${ }^{31,45}$ Thus, modifying the passage of air through the nasal cavity, even without deterioration of nasal resistance, changes patient perception and can trigger nasal obstruction perception.

We found no major difference between NOSE and VAS in their correlation with CFD, their degree of correlation varying according to the different studies. We recommend using both, as well as more targeted questionnaires such as the ENS6Q for ENS.

\section{3 | Limitations}

Comparing clinical data with CFD remains a difficult exercise. To do so, however, authors have several options: they can either compare healthy and pathological subjects or compare the same patient before and after surgery. Alternatively, they can compare clinical tests with CFD. There are many reasons why such studies are still difficult to perform on large populations of subjects. Firstly, postoperative CT scans are not always justified since CT scans expose patients to additional radiation. Moreover, calculation and implementation times are still long and often require the presence of an IT specialist as the currently available software is not user-friendly for surgeons. Recent software appears to be easier to use, including automatic generation of the nasal geometry and computational mesh in the nasal cavity. ${ }^{46}$ The software can perform CFD in the nasal cavity (solving the Navier-Strokes equation) using different boundary conditions, types of airflows (laminar or turbulent) and breathing phases (inspiration or expiration).

\subsection{Potential biases in the review}

Of the studies reviewed, one did not include a validated assessment of nasal obstruction but simply reported a difference in clinical impairment between the compared groups. ${ }^{24}$ However, given the number of studies, we incorporated all those that report patient perception. In some cases, correlations occasionally appear to be present although their significance remains unconfirmed by a satisfactory statistical test due to the small number of patients included. It is essential therefore to conduct further studies on larger populations of patients.

\subsection{Implication for research}

In future, we must be able to perform more frequent inspiratory and expiratory simulations based on normal breathing (and not on a constant incoming airflow). This is essential to allow deformation of nasal walls, which play a major role in nasal valve collapse, and in order to integrate new types of data such as hygrometry to measure the humidity in the atmosphere and to vary the temperature of the nasal mucosa according to inspiration or expiration. This will help generate more reliable extrapolation of CFD results. Application of CFD protocols to clinical cases of nasal obstruction will help define the best treatment of the disease (surgery, non-invasive or minimally invasive therapy).

\section{5 | CONCLUSION}

The growing number of CFD studies involving the nose is helping to improve our understanding of nasal obstruction. The clinical interpretation of previously unknown data, such as WSS and heat flux, is 
opening up new horizons in our knowledge regarding this symptom. Heat fluxes are among the most accurate CFD values correlated with patient perception. Further studies on larger cohorts of patients are needed.

\section{CONFLICT OF INTERESTS}

None to declare.

\section{ORCID}

Thomas Radulesco (D) https://orcid.org/0000-0002-5939-5372

\section{REFERENCES}

1. Rhee JS, Book DT, Burzynski M, Smith TL. Quality of life assessment in nasal airway obstruction. The Laryngoscope. 2003;113:1118-1122.

2. Frank-Ito DO, Kimbell JS, Laud P, Garcia GJ, Rhee JS. Predicting postsurgery nasal physiology with computational modeling: current challenges and limitations. Otolaryngol Head Neck Surg. 2014;151:751-759.

3. Rhee JS, Sullivan CD, Frank DO, Kimbell JS, Garcia G. A systematic review of patient-reported nasal obstruction scores: defining normative and symptomatic ranges in surgical patients. JAMA Facial Plast Surg. 2014;16(3):219.

4. Vogt K, Wernecke K-D, Behrbohm H, Gubisch W, Argale M. Four-phase rhinomanometry: a multicentric retrospective analysis of 36,563 clinical measurements. Eur Arch Otorhinolaryngol. 2016;273:1185-1198.

5. Pendolino AL, Nardello E, Lund VJ, et al. Comparison between unilateral PNIF and rhinomanometry in the evaluation of nasal cycle. Rhinology. 2018;56:122-126.

6. Chen XB, Lee HP, Chong VF, de Wang Y. Numerical simulation of the effects of inferior turbinate surgery on nasal airway heating capacity. Am J Rhinol Allergy. 2010;24(5):e118-e122.

7. Dayal A, Rhee JS, Garcia GJ. Impact of middle versus inferior total turbinectomy on nasal aerodynamics. Otolaryngol Head Neck Surg. 2016;155:518-525.

8. Kimbell JS, Frank DO, Laud P, Garcia GJ, Rhee JS. Changes in nasal airflow and heat transfer correlate with symptom improvement after surgery for nasal obstruction. J Biomech. 2013;46:2634-2643.

9. Rhee JS, Cannon DE, Frank DO, Kimbell JS. Role of virtual surgery in preoperative planning: assessing the individual components of functional nasal airway surgery. Arch Facial Plast Surg. 2012;14:354-359.

10. Otto BA, Li C, Farag AA, et al. Computational fluid dynamics evaluation of posterior septectomy as a viable treatment option for large septal perforations. Int Forum Allergy Rhinol. 2017;7:718-725.

11. Leite S, Jain R, Douglas RG. The clinical implications of computerised fluid dynamic modelling in rhinology. Rhinology. 2019;57:2-9.

12. Shadfar S, Shockley WW, Fleischman GM, et al. Characterization of postoperative changes in nasal airflow using a cadaveric computational fluid dynamics model: supporting the internal nasal valve. JAMA Facial Plast Surg. 2014;16:319-327.

13. Moher D, Shamseer L, Clarke M, et al. Preferred reporting items for systematic review and meta-analysis protocols (PRISMA-P) 2015 statement. Syst Rev. 2015;4:1.

14. Floyd EM, Ho S, Patel P, Rosenfeld RM, Gordin E. Systematic review and meta-analysis of studies evaluating functional rhinoplasty outcomes with the NOSE Score. Otolaryngol Head Neck Surg. 2017;156:809-815.
15. Hsu HC, Tan CD, Chang CW, et al. Evaluation of nasal patency by visual analogue scale/nasal obstruction symptom evaluation questionnaires and anterior active rhinomanometry after septoplasty: a retrospective one-year follow-up cohort study. Clin Otolaryngol. 2017;42:53-59.

16. Stewart MG, Witsell DL, Smith TL, Weaver EM, Yueh B, Hannley MT. Development and validation of the nasal obstruction symptom evaluation (NOSE) scale. Otolaryngol Head Neck Surg. 2004;130:157-163.

17. Lipan MJ, Most SP. Development of a severity classification system for subjective nasal obstruction. JAMA Facial Plast Surg. 2013;15:358-361.

18. Erskine SE, Hopkins C, Clark A, et al. SNOT-22 in a control population. Clin Otolaryngol. 2017;42:81-85.

19. Velasquez N, Thamboo A, Habib A-R, Huang Z, Nayak JV. The Empty Nose Syndrome 6-Item Questionnaire (ENS6Q): a validated 6-item questionnaire as a diagnostic aid for empty nose syndrome patients. Int Forum Allergy Rhinol. 2017;7:64-71.

20. Geißler K, Guntinas-Lichius O. Rhinomanometry and acoustic rhinometry. Laryngorhinootologie. 2015;94:8-9.

21. Casey KP, Borojeni AA, Koenig LJ, Rhee JS, Garcia GJ. Correlation between subjective nasal patency and intranasal airflow distribution. Otolaryngol Head Neck Surg. 2017;156:741-750. Epub 2017 Jan 31.

22. Gaberino C, Rhee JS, Garcia GJ. Estimates of nasal airflow at the nasal cycle mid-point improve the correlation between objective and subjective measures of nasal patency. Respir Physiol Neurobiol. 2017;238:23-32.

23. Chen XB, Lee HP, Chong VF, de Wang Y. Assessments of nasal bone fracture effects on nasal airflow: A computational fluid dynamics study. Am J Rhinol Allergy. 2011;25:e39-43.

24. Kim SK, Heo GE, Seo A, Na Y, Chung SK. Correlation between nasal airflow characteristics and clinical relevance of nasal septal deviation to nasal airway obstruction. Respir Physiol Neurobiol. 2014;192:95-101

25. Keeler J, Most SP. Measuring nasal obstruction. Facial Plast Surg Clin North Am. 2016;24:315-322.

26. Zhao K, Jiang J, Blacker $\mathrm{K}$, et al. Regional peak mucosal cooling predicts the perception of nasal patency. Laryngoscope. 2014;124:589-595.

27. Lu J, Han D, Zhang L. Accuracy evaluation of a numerical simulation model of nasal airflow. Acta Otolaryngol. 2014;134:513-519.

28. Naughton JP, Lee AY, Ramos E, Wootton D, Stupak HD. Effect of nasal valve shape on downstream volume, airflow, and pressure drop: importance of the nasal valve revisited. Ann Otol Rhinol Laryngol. 2018;127:745-753.

29. Liu T, Han D, Wang J, et al. Effects of septal deviation on the airflow characteristics: using computational fluid dynamics models. Acta Otolaryngol. 2012;132:290-298.

30. Li C, Farag AA, Leach J, et al. Computational fluid dynamics and trigeminal sensory examinations of empty nose syndrome patients. Laryngoscope. 2017;127:E176-E184.

31. Li C, Farag AA, Maza G, et al. Investigation of the abnormal nasal aerodynamics and trigeminal functions among empty nose syndrome patients. Int Forum Allergy Rhinol. 2018;8:444-452.

32. Barone M, Cogliandro A, Di Stefano N, Tambone V, Persichetti P. A systematic review of patient-reported outcome measures after rhinoplasty. Eur Arch Otorhinolaryngol. 2017;274:1807-1811.

33. Pawar SS, Garcia G, Kimbell JS, Rhee JS. Objective measures in aesthetic and functional nasal surgery: perspectives on nasal form and function. Facial Plast Surg FPS. 2010;26:320-327.

34. Zhao K, Blacker K, Luo Y, Bryant B, Jiang J. Perceiving nasal patency through mucosal cooling rather than air temperature or nasal resistance. PLoS One. 2011;6:e24618.

35. Inthavong K, Ma J, Shang $\mathrm{Y}$, et al. Geometry and airflow dynamics analysis in the nasal cavity during inhalation. Clin Biomech 
(Bristol Avon). 2019;66:97-106. https://doi.org/10.1016/j.clinb iomech.2017.10.006

36. Lindemann J, Tsakiropoulou E, Scheithauer MO, Konstantinidis I, Wiesmiller KM. Impact of menthol inhalation on nasal mucosal temperature and nasal patency. Am J Rhinol. 2008;22:402-405.

37. Sullivan CD, Garcia GJ, Frank-Ito DO, Kimbell JS, Rhee JS. Perception of better nasal patency correlates with increased mucosal cooling after surgery for nasal obstruction. Otolaryngol Head Neck Surg. 2014;150:139-147.

38. Roithmann R, Cole P, Chapnik J, Barreto SM, Szalai JP, Zamel N. Acoustic rhinometry, rhinomanometry, and the sensation of nasal patency: a correlative study. J Otolaryngol. 1994;23:454-458.

39. Naito K, Komori M, Kondo Y, Takeuchi M, Iwata S. The effect of Lmenthol stimulation of the major palatine nerve on subjective and objective nasal patency. Auris Nasus Larynx. 1997;24:159-162.

40. Chandra RK, Patadia MO, Raviv J. Diagnosis of nasal airway obstruction. Otolaryngol Clin North Am. 2009;42(2): 207-225. vii.

41. Kahana-Zweig R, Geva-Sagiv M, Weissbrod A, Secundo L, Soroker $\mathrm{N}$, Sobel N. Measuring and characterizing the human nasal cycle. PLoS One. 2016;11:e0162918.

42. Patel RG, Garcia G, Frank-Ito DO, Kimbell JS, Rhee JS. Simulating the nasal cycle with computational fluid dynamics. OtolaryngolHead Neck Surg. 2015;152:353-360.

43. Bloching MB. Disorders of the nasal valve area. GMS Curr Top Otorhinolaryngol. Head Neck Surg. 2007;6:Doc07.
44. Aksoy F, Veyseller B, Yildirim YS, Acar H, Demirhan H, Ozturan O. Role of nasal muscles in nasal valve collapse. Otolaryngol-Head Neck Surg. 2010;142:365-369.

45. Nyte CP. Hyaluronic acid spreader-graft injection for internal nasal valve collapse. Ear Nose Throat J. 2007;86:272-273.

46. Xavier R, Azeredo-Lopes S, Papoila A. Spreader grafts: functional or just aesthetical? Rhinology. 2015;53:332-339.

47. Balakin BV, Farbu E, Kosinski P. Aerodynamic evaluation of the empty nose syndrome by means of computational fluid dynamics. Comput Methods Biomech Biomed Engin. 2017;20:1554-1561.

\section{SUPPORTING INFORMATION}

Additional supporting information may be found online in the Supporting Information section at the end of the article.

How to cite this article: Radulesco T, Meister L, Bouchet G, et al. Functional relevance of computational fluid dynamics in the field of nasal obstruction: A literature review. Clin Otolaryngol. 2019;00:1-9. https://doi.org/10.1111/coa.13396 